\title{
Prospects for the Adoption of Agile Project Management Techniques in Nigerian Construction Industry
}

\author{
O. P. Esangbedo*, D. E. Ealefoh \\ Department of Building Technology, National Institute of Construction Technology and Management, Edo State, NIGERIA.
}

\begin{abstract}
Persistent failure of construction projects to meet clients' objectives has compelled a review of the extant systems for project delivery. This study assessed the prospect of adopting Agile Project Management (APM) for construction project delivery in Lagos State. To achieve this, the study examined the level of awareness of APM among construction stakeholders and developed a SWOT model for the adoption of APM technique for construction projects. The research adopted survey method using questionnaire. The study sample involved 196 construction stakeholders. Data obtained were analysed using Mean Score and Fussy Set Theory. The result showed that stakeholders' level of awareness about the individual methodologies of APM is high. There are also weighty strengths, weaknesses, opportunities and threats in the adoption of APM in construction project delivery. The level of awareness among stakeholders portrays high prospects for APM adoption. However, there is need to embed trust, cooperation and improved team performance.
\end{abstract}

Keywords: agile, project management, construction industry, fussy set theory, construction stakeholders, SWOT

\section{INTRODUCTION}

The critical nature of clients' requirements means that project managers who lead and manage project should make use of best approaches. Although, this is often times not an easy task for project managers because, construction projects are large, it involves many disciplines and include high-risks that are usually constrained by time and budget [1]. Based on these characteristics, delivering on project objectives using the conventional or traditional project management expertise is faced with enormous challenges [2]. To improve project performance, it is important to have efficient methodologies which take into consideration that the projects are often initiated under uncertainties [3].

Poor performance of construction projects in Lagos State arising from failures of prevalent traditional project management practices to address the changing needs of contemporary project delivery is addressed in this study. Several mega projects in Nigeria strays behind standard project performance objectives [4].

The construction industry in Nigeria is outstanding for its poor performance in terms of cost overrun in projects, poor project planning and

\footnotetext{
* Corresponding author (Tel: +234(0) 703565 1238)

Email addresses: paulesangbedo@gmail.com (O. P. Esangbedo), ealefohdominic@gmail.com (D. E. Ealefoh)
}

control, poor project completion times and compliance with deadlines, and an increase in rework and defects [5]. Many construction projects in Lagos State have experienced a lot of problems on site. The problems, to mention but a few, are delays, poor management, complexity and risk [5]. The extant failures of building projects can be attributed to the traditional approach of procuring building projects [2]. The traditional approach lacks collaboration, and enhances isolation among the construction professionals or stakeholders with regards to the building project delivery process, and this does not satisfy the clients' need and generic solutions can be copied and re-used. The aim of this study is to assess the prospects for the adoption of agile project management techniques in the construction industry in Lagos State, Nigeria using SWOT analysis model towards improved construction project performance. In order to achieve the aim, the specific objectives were set:

I. Examine level of awareness of agile project management technique for the execution of building and civil engineering construction projects by project stakeholders.

II. Develop a SWOT model for the adoption of Agile Project Management technique for construction projects. 
Table 1: Profile of Respondents.

\begin{tabular}{llccc}
\hline \multirow{3}{*}{ Profession } & & \multicolumn{2}{c}{ Area of specialty } & Grand Total \\
\hline \multirow{5}{*}{ Consultant } & Building works Civil works & Grandect \\
& Architect & 4 & 9 & 13 \\
& Builder & 11 & 0 & 11 \\
& Q/S & 10 & 16 & 26 \\
& Civil engineer & 0 & 22 & 22 \\
& Total respondent & 25 & 47 & 72 \\
Contractor & Architect & 14 & 0 & 14 \\
& Builder & 41 & 0 & 41 \\
& Q/S & 3 & 19 & 22 \\
& Civil engineer & 2 & 5 & 8 \\
\hline \multicolumn{1}{l}{ Overall total } & Total respondent & 60 & 24 & 156 \\
\hline
\end{tabular}

\section{LITERATURE REVIEW}

\subsection{Agile Project Management}

Agile project management is an iterative process that focuses on customer value first, interaction over tasks, and adapting to current business reality rather than following a prescriptive plan [6]. The agile approach is about breaking down large and complex deliverables into many partial deliveries in an incremental way. This is done to receive feedback from the project client, which leads to the incorporation of the customer's experience. It allows the customer to influence the development of the project, as well as controlling and regulating the structure of the project. Agile project management system improves the contractor's ability to rapidly adapt to job site changes, minimising the time between when a risk is detected and when it is corrected [7]. In addition, the implementation of Agile construction management brings also ensures highly motivated and trained work methodology during design phases by creating greater consumer value [8].

However, the uses of agile in the construction project delivery focused on reducing the negative impacts of variability, making projects more predictable, minimising buffers, reducing uncertainties, improving collaborative planning, creating reliable work plans [9].

\section{METHODOLOGY}

Survey research design was used to obtain opinions of project stakeholders on pertinent issues bordering on agile project management adoption within Lagos State. The population frame of the study comprised of professionals engaged as consultants and contractors in Building and Civil Engineering projects in Lagos State, Nigeria. The population of 384 construction professionals comprising Architects, Builders, Quantity Surveyors and Civil Engineer were obtained through preliminary inquiries and consultation of the registry of consultants and contractors' organisations in Lagos State. Random sampling method, which is a method under the probability sampling techniques, was chosen so that every member of the parent population would have equal opportunities or chances of being selected in the sample. The sample size was obtained using the Taro Yamene's formula as used in a study by Nwakpa [10] as seen in the following section.

The Taro Yamene formula is:

$$
n=\frac{N}{1+N(e)^{2}}
$$

Where: $n=$ sample size sought, $N=$ Population size (384) and $e=$ Level of significance (0.05).

Substituting into the equation, we have

$$
\begin{aligned}
n & =\frac{384}{1+384(0.05)^{2}} \\
& =\frac{384}{1+0.94} \\
& =\frac{384}{194} \\
& =195.9 \\
& =196
\end{aligned}
$$

Field data were developed into database management system using SPSS. Data analysis therefore involved statistical tools, mainly nonparametric because, their sources were ordinal scale of measurement. Mean scores of $\geq 4$ is rated as very high, $>3.0<4.00$ is rated as high.

The model was developed having analysed the strengths, weaknesses, opportunities and threats of agile project management using the Fuzzy Set Theory (FST). This theory helps to identify the critical elements amongst all identified challenges. The main reason to apply this theory is because of fuzziness and uncertainty in subjective responses due to imprecision or vagueness [11]. The procedure involves calculation of Mean scores (MS), standard deviations (SD), and Z-score and degree of association using 'Excel Norm-Dist' tool [12]. For this study, $\lambda=0.70$ was adopted in order to identify the critical strengths, weaknesses, opportunities and threats, following the work of Shen [11].

\section{RESULTS AND DISCUSSION OF FINDINGS}

Table 1 shows over $46.15 \%$ of the total sample are consultant and $65.28 \%$ specializes in civil engineering work, while $34.72 \%$ are specialist in 
building work. $53.8 \%$ are contractor where 28 . $57 \%$ specializes in civil engineering works while $71.43 \%$ specializes in building works.

Table 2 shows significant level of awareness among construction stakeholder in civil engineering project and building projects. In the construction stakeholders' awareness about eight Agile methodologies in civil engineering projects are very high namely: building the project around sets of motivated individuals, most efficient and effective method of conveying information, continuous attention to technical excellence, integration of information technology, early delivery of project to satisfy clients, self-organising team, continuous improvement based on learning, facilitating project goals since deadlines could be set more frequently. Methodologies with high awareness are: deciding sprint event before commencement, delivering working sprint more frequently, welcome changing requirement even late in the project development, short term planning with concurrent execution, and monitoring sprint resources. This shows that the sample of construction stakeholder surveyed understands the workings and principles of Agile methodologies in improving project delivery for better performance.

Whereas in the construction stakeholders' awareness on building projects about four Agile methodologies are very high namely: building the project around sets of motivated individuals, efficient and effective method of conveying information to and within a development team is faceto-face conversation, best architectures, requirements, and designs emerge from self-organizing teams, and priority to satisfy the clients through early and continuous delivery of projects. The other nine methodologies received high awareness rating including: deciding sprint event before commencement, delivering working sprint more frequently, welcome changing requirement even late in the project development, short term planning with concurrent execution, and monitoring sprint resources.

The data underpinning the model developed below is based on perceptual ranking of the respondents, ordinal data was therefore collected using the research instrument to achieve this objective of the study. The analysis of these data adopted Fussy Set Theory to determine the critical performance of the identified strengths as the significant drivers of the prospect of agile project management practices adoption in the study area, significant inhibitors of the prospects to adopt agile project management practices, germane opportunities to be optimized and threats to be mitigated. Strengths of Agile Project Management Systems

The opinion of respondents about the strengths that could drive the adoption of agile project management in the construction industry was determined, and the results is presented in Table 3.

\subsection{Weaknesses of Agile Project Manage- ment Practices}

Table 4 presents the weaknesses of the agile project management system that could inhibit their adoption in the study area

\subsection{Opportunities of Agile Project Manage- ment Systems}

Table 5 presents the opportunities in adopting agile project management systems using FST.

\subsection{Threats to the Adoption of Agile Project Management Systems}

Table 6 resents the criticality of the identified threats to the adoption of agile project management systems in the study area using FST.

The mean score of accepted variables are:

- Strengths $(\mathrm{S})=66.07$

- Weaknesses $(\mathrm{W})=30.71$

- Opportunities $(\mathrm{O})=39.44$

- $\operatorname{Threats}(\mathrm{T})=54.16$

Since $\mathrm{T}>\mathrm{O}$ and $\mathrm{S}>\mathrm{W}$, therefore $\mathrm{S}+\mathrm{T}$ is the response for the adoption of APM in Lagos State.

\section{CONCLUSION}

The study assessed the prospects of adoption of Agile project management in the construction industry in Lagos State using the SWOT analysis model. The result obtained from data analysis showed and highlighted the strengths, weakness, opportunities and threats of agile methodology in Lagos State, Nigeria. The level of awareness of the discrete components of the agile project management systems among construction stakeholders gives a mean score of $\geq 4$. Although the level of awareness relates to individual segments of agile project management system, the adoption of integrated agile project management system may not be difficult since stakeholders are already aware of most of the components of the APM technique. Other results also showed that strengths, weaknesses, opportunities and threats of agile project management systems are satisfactory. The implication is that the strength of agile project management systems is satisfactory to drive its adoption in project implementation. Similarly, the opportunities of this project management systems are also enormous and significant to support their adoption in construction project delivery. At the same vein, the results also showed that inherent weaknesses and threats in agile project management can inhibits and dim the strengths and opportunities for marketing their adoption in the construction industry. The implication therefore suggests that the inherent opportunities must to be optimised, while maximising the strengths of the project management system. It is also important to improve inherent weaknesses of the system, while mitigating inherent to optimal adoption in construction project delivery. 
Table 2: Level of Construction Stakeholders Awareness of Agile Methodologies .

\section{Codes Agile Methodology}

APM1 Build projects around motivated individuals. Give them the environment and support they need and trust them to get the job done

APM2 The most efficient and effective method of conveying information to and within a development team is face-to-face conversation

APM3 The best architectures, requirements emerge from self-organizing teams.

APM4 Highest priority is to satisfy the clients through early and continuous delivery of projects.

APM5 Delivers working sprints frequently, from a couple of weeks to a couple of months

APM6 Welcome changing requirements

APM7 Continuous attention to technical excellence and good design enhances agility

APM8 Resource monitoring of sprints

APM9 Short term planning along with concurrent execution of activities

APM10 Continuous improvement based on learning of team members

APM11 Facilitates project goals since deadlines could be set more frequently

APM12 Before each sprint is started, the team and the product owner meets to decide which items from the product backlog should go into the sprint backlog

\begin{tabular}{cccccc}
\multicolumn{2}{c}{$\begin{array}{c}\text { Civil Engineering project } \\
\text { Mean }\end{array}$} & \multicolumn{3}{c}{ Rank } & Remailding Projects \\
Remark & Mean Rank & Remark \\
\hline 4.63 & 1st & Very high & 4.13 & 2nd & Very high
\end{tabular}

4.33 4th Very high 4.23 1st Very high

4.26 6th Very high 4.03 3rd Very high

$4.30 \quad 5$ th $\quad$ Very high $\quad 4.00 \quad 4$ th $\quad$ Very high

3.87 10th High 3.96 5th High

3.87 10th High 3.96 5th High

4.35 2nd Very high 3.95 6th High

3.76 12th High 3.93 7th High

3.80 11th High 3.89 8th High

4.19 7th Very high 3.88 9th High

4.08 8th Very high 3.86 10th High

3.90 9th High 3.85 11th High

4.35 2nd Very high $3.80 \quad$ 12th High

Table 3: FST Analysis of the Strengths of Agile Project Management.

\begin{tabular}{|c|c|c|c|c|c|c|}
\hline Codes & Variables & MS & Std. D & $\mathbf{Z S}$ & $\mathbf{M}(\mathbf{x i})$ & Remark \\
\hline APS1 & High client satisfaction & 4.53 & 0.67 & 2.29 & 0.99 & $\checkmark$ \\
\hline APS2 & Good motivation among team members & 4.33 & 0.56 & 2.38 & 0.99 & $\checkmark$ \\
\hline APS3 & Increase technical excellence among team & 4.26 & 0.58 & 2.18 & 0.99 & $\checkmark$ \\
\hline APS4 & $\begin{array}{l}\text { Excellent and collaborative working relationship } \\
\text { among project stakeholders }\end{array}$ & 4.24 & 0.53 & 2.32 & 0.99 & $\checkmark$ \\
\hline APS5 & $\begin{array}{l}\text { Issues related to clients requirements are solved and } \\
\text { answered immediately }\end{array}$ & 4.23 & 0.56 & 2.22 & 0.99 & $\checkmark$ \\
\hline APS6 & $\begin{array}{l}\text { Constant inspection and integration which ensures } \\
\text { correction of fault regularly }\end{array}$ & 4.18 & 0.61 & 1.95 & 0.97 & $\checkmark$ \\
\hline APS7 & $\begin{array}{l}\text { Client can evaluate project after each iteration and } \\
\text { suggest plans for the future }\end{array}$ & 4.15 & 0.51 & 2.26 & 0.99 & $\checkmark$ \\
\hline APS8 & Quick adaptation to change & 4.13 & 0.83 & 1.35 & 0.91 & $\checkmark$ \\
\hline APS9 & It involves creative brainstorming & 4.13 & 0.45 & 2.51 & 0.99 & $\checkmark$ \\
\hline APS10 & Progress is viewed and measured after each iteration & 4.11 & 0.52 & 2.15 & 0.98 & $\checkmark$ \\
\hline APS11 & $\begin{array}{l}\text { Continued channel of communication between team } \\
\text { members which increases job satisfaction }\end{array}$ & 4.10 & 0.40 & 2.79 & 1.00 & $\checkmark$ \\
\hline APS12 & Based on people and their creativity & 4.07 & 7.63 & 0.14 & 0.56 & - \\
\hline APS13 & Its main aim is to improve function at reduced cost & 4.06 & 0.65 & 1.64 & 0.95 & $\checkmark$ \\
\hline APS14 & Client's interest in the use of the technique & 4.00 & 0.75 & 1.34 & 0.91 & $\checkmark$ \\
\hline APS15 & $\begin{array}{l}\text { Philosophy based on the idea that projects are } \\
\text { developed in short iterations }\end{array}$ & 3.95 & 0.55 & 1.71 & 0.96 & $\checkmark$ \\
\hline APS16 & Decentralization control of management team & 3.90 & 0.90 & 1.00 & 0.84 & $\checkmark$ \\
\hline APS17 & Project team members are often pleased more & 3.77 & 0.96 & 0.80 & 0.79 & $\checkmark$ \\
\hline
\end{tabular}


Table 4: FST Analysis of the Weakness of Agile Project Management.

\begin{tabular}{|c|c|c|c|c|c|c|}
\hline Codes & Variables & MS & Std. D & $\mathbf{Z S}$ & $\mathbf{M}(\mathbf{x i})$ & Remark \\
\hline APW1 & Requires professional to form teams & 4.08 & 0.83 & 1.30 & 0.90 & $\checkmark$ \\
\hline APW2 & Difficulty in coordinating between teams for large projects & 3.93 & 1.01 & 0.92 & 0.82 & $\checkmark$ \\
\hline APW3 & Lack of stakeholders' awareness on the benefit of the technique & 3.85 & 0.89 & 0.95 & 0.83 & $\checkmark$ \\
\hline APW4 & $\begin{array}{l}\text { Customer interaction- not all customers find time to spend } \\
\text { with the team }\end{array}$ & 3.83 & 0.93 & 0.90 & 0.82 & $\checkmark$ \\
\hline APW5 & $\begin{array}{l}\text { Requires meetings at frequent intervals at enormous expense } \\
\text { to clients }\end{array}$ & 3.83 & 0.85 & 0.97 & 0.83 & $\checkmark$ \\
\hline APW6 & Change in management style & 3.81 & 0.93 & 0.87 & 0.81 & $\checkmark$ \\
\hline APW7 & Lack of enough documentation for tracking overall progress & 3.73 & 1.09 & 0.67 & 0.84 & $\checkmark$ \\
\hline APW8 & Lack of long term planning & 3.65 & 1.13 & 0.58 & 0.72 & $\checkmark$ \\
\hline APW9 & $\begin{array}{l}\text { Can increase the risk of scope creep due to the act of detailed } \\
\text { requirements documentation }\end{array}$ & 3.53 & 1.18 & 0.44 & 0.67 & - \\
\hline APW10 & $\begin{array}{l}\text { Impossible to develop realistic estimates of work efforts needed } \\
\text { to provide a quote }\end{array}$ & 3.51 & 0.99 & 0.49 & 0.69 & - \\
\hline APW11 & Can lead to more difficult contractual negotiations & 3.47 & 1.21 & 0.39 & 0.65 & - \\
\hline APW12 & Issues of organizational structure/culture & 3.45 & 0.91 & 0.49 & 0.69 & - \\
\hline APW13 & $\begin{array}{l}\text { Often used as a means to bleed money from client through lack } \\
\text { of defining a deliverable }\end{array}$ & 3.20 & 1.07 & 0.19 & 0.57 & - \\
\hline
\end{tabular}

Table 5: FST Analysis of the opportunities of Agile Project Management.

\begin{tabular}{llccccc}
\hline Codes & Opportunities & MS & SD & ZS & M(xi) & Remark \\
\hline APO1 & Emphasises commitment and leadership among team members & 4.22 & 0.51 & 2.38 & 0.99 & $\checkmark$ \\
APO2 & Enhances quality of work & 4.17 & 0.48 & 2.42 & 0.99 & $\checkmark$ \\
APO3 & Agile practices increases commitment of team members & 4.07 & 0.55 & 1.96 & 0.98 & $\checkmark$ \\
APO4 & Enhances coaching and mentoring among construction practitioners & 4.06 & 0.59 & 1.81 & 0.97 & $\checkmark$ \\
APO5 & Enhances self-organizing team & 4.04 & 0.47 & 2.22 & 0.99 & $\checkmark$ \\
APO6 & Encourages continuous training and education of stakeholders & 4.01 & 0.55 & 1.86 & 0.97 & $\checkmark$ \\
APO7 & Agile practices increases motivation of team members & 3.99 & 0.56 & 1.78 & 0.96 & $\checkmark$ \\
APO8 & Commitment and co-operation of professional bodies to the & 3.80 & 0.63 & 1.26 & 0.90 & $\checkmark$ \\
& implementation of the technique & & & & & \\
APO9 & High clients dissatisfaction with project deliverables under & 3.62 & 0.96 & 0.65 & 0.74 & $\checkmark$ \\
& other project management techniques & & & & & \\
APO10 & Government support through legislation & 3.51 & 1.03 & 0.49 & 0.69 & \\
APO11 & Inability of traditional project management methods to cope & 3.46 & 0.84 & 0.55 & 0.71 & $\checkmark$ \\
& with increasing complexity of construction project & & & & & \\
APO12 & Academic and professional acceptance & 3.38 & 1.00 & 0.38 & 0.65 & - \\
APO13 APM methodology is successful in other industry & 3.30 & 0.81 & 0.37 & 0.65 & - \\
\hline
\end{tabular}

Table 6: FST Analysis of the Threats of Agile Project Management.

\begin{tabular}{llccccc}
\hline Codes & Variables & MS & SD & ZS & M(xi) & Remark \\
\hline APT1 & APM requires team trust & 4.23 & 0.94 & 1.31 & 0.90 & $\checkmark$ \\
APT2 & APM requires team cooperation & 4.10 & 0.53 & 2.07 & 0.98 & $\checkmark$ \\
APT3 & Requires highly competent professionals as team members & 3.96 & 0.88 & 1.09 & 0.86 & $\checkmark$ \\
APT4 & Lack of personnel training & 3.90 & 0.72 & 1.25 & 0.89 & $\checkmark$ \\
APT5 & Lack of collaboration with team partners & 3.89 & 0.49 & 1.81 & 0.96 & $\checkmark$ \\
APT6 & Lack of management support & 3.87 & 0.94 & 0.92 & 0.82 & $\checkmark$ \\
APT7 & Unavailability and access to different stakeholders & 3.84 & 0.88 & 0.95 & 0.83 & $\checkmark$ \\
APT8 & Lack of adequate experience of team members & 3.83 & 0.93 & 0.90 & 0.82 & $\checkmark$ \\
APT9 & Poor working relationship with team members & 3.83 & 1.01 & 0.83 & 0.80 & $\checkmark$ \\
APT10 & Stakeholders resistance to its introduction and implementation & 3.83 & 0.95 & 0.88 & 0.81 & $\checkmark$ \\
APT11 & Lack of awareness or staff knowledge of agile project management & 3.80 & 0.89 & 0.90 & 0.82 & $\checkmark$ \\
APT12 & Difficulties in the involvement of all key stakeholders in project & 3.77 & 0.95 & 0.81 & 0.79 & $\checkmark$ \\
& processes & & & & & \\
APT13 & Requires too much organizational change & 3.72 & 0.89 & 0.81 & 0.79 & $\checkmark$ \\
APT14 & Fear of incurring additional cost attributable to the use of agile & 3.59 & 0.96 & 0.62 & 0.73 & $\checkmark$ \\
& project management & & & & & \\
APT15 & Customer Bureaucracy & 3.47 & 0.92 & 0.51 & 0.69 & - \\
APT16 & Inflexible procurement system & 3.46 & 0.97 & 0.47 & 0.68 & - \\
\hline
\end{tabular}




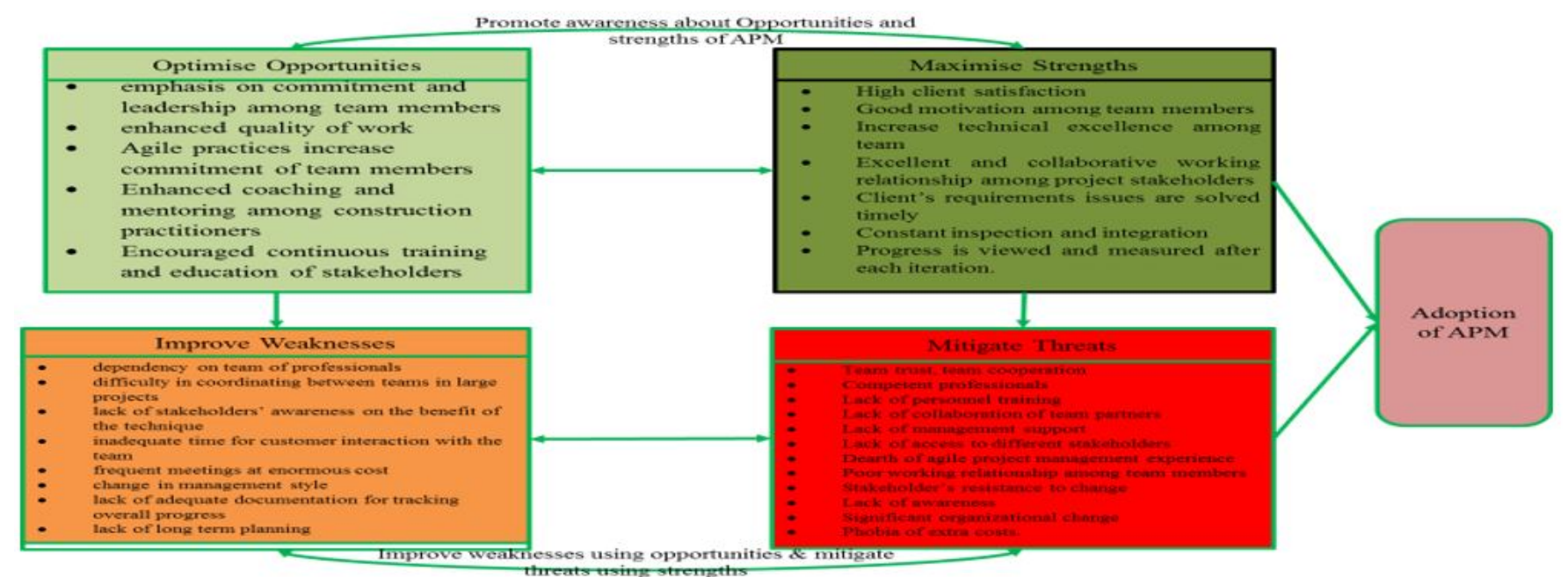

Figure 1: SWOT Model for the adoption of APM.

\section{RECOMMENDATION}

Based on the results of the study, the following are the recommendations:

1. Since there is significant level of awareness among construction stakeholders about agile project management tool, piloting the project management techniques through their application in real-life project implementation is imperative to facilitate diffused adoption across varying projects and sectors of the construction industry. Diffused adoption also means piloting the tool must be supported with proper training of construction stakeholders through seminars, projectbased training, workshops, and conferences.

2. Construction stakeholders are also enjoined to bank on the potential strengths and opportunities of APM to de-market traditional project management techniques towards significant uptake of agile project management for improved efficiency and timely delivery of construction projects.

3. Stakeholders must also take steps to improve the perceived weaknesses of the Agile Project Management to maximize it strengths and opportunities for effective promotion, marketing, and adoption of its tools.

4. At the same time, perceived threats (risks) must be mitigated by re-engineering the APM tools based on local construction industry norms, experiences and protocols to avoid practice dubbing that might be incompatible with the cultural norms and project requirements in the in-country context.

\section{References}

[1] Willis' Practice and Procedure for Quantity Surveyors. Oxford: Blackwell Science Publishers, 2013.

[2] J. Fewell, M. Jack, D. Prior, P. Rosado, and B. Tarne, "Challenges in implementing agile project management," in PMI Global Congress 2009-EMEA, North Holland, The Netherlands, newtown Square, PA: Project Management Institute.
[3] G. Winch, Managing construction projects, 2nd ed. Manchester: Wiley, 2010.

[4] S. Ekung, L. Agu, and N. Iheama, "Influence of Project Governance on Project Performance: Evidence from Nigerian Case Studies," PM World Journal, vol. 6, no. 8, pp. $1-18,2017$.

[5] N. Dim, A. Ezeabasili, and B. Okoro, "Managing the change process associated with BIM Implementation by the Public and private investors in the Nigerian Building Industry," Dannish Journal of Engineering and Manufacturing Technology, vol. 2, no. 1, pp. 1-6, 2015.

[6] E. Conforto, D. Amaral, S. Silva, A. Felippo, and D. Kamikawachi, "The agility construct on project management theory," International Journal of Project Management, vol. 34, pp. 660-674, 2016.

[7] P. Daneshgari and P. Daneshgari, Agile construction for the electrical contractor. Jones \& Bartlett Learning, 2010.

[8] A. Opelt, B. Gloger, W. Pfarl, and R. Mittermayr, Agile contracts - Creating and managing successful projcts with scrum. New Jersey: John Wiley \& Sons, Inc., 2013.

[9] L. Koskela, R. Stratton, and A. Koskenvesa, "Last planner and critical chain in construction management: comparative analysis," National Building Research Institute, Haifa, Israel, 2010, 538-547.

[10] N. Nwankpa, "Nigerian Newspaper Coverage of Militancy in the Niger Delta and Readers' perception," Ph.D. dissertation, University of Uyo, Nigeria, 2011.

[11] L. Shen, W. Lu, Y. Peng, and S. Jiang, "Critical assessment indicators formeasuring benefits of rural infrastructure investment in China," Journal of Infrastructure Systems, vol. 17, no. 4, pp. 176-183, 2012.

[12] H. Zimmermann, Fuzzy Set Theory and Its Applications, 4th ed. London: Kluwer Academic, 2011. 